\title{
Knowledge and practices related to diabetes mellitus among adults with diabetes in the Mopani District, Limpopo Province, South Africa
}

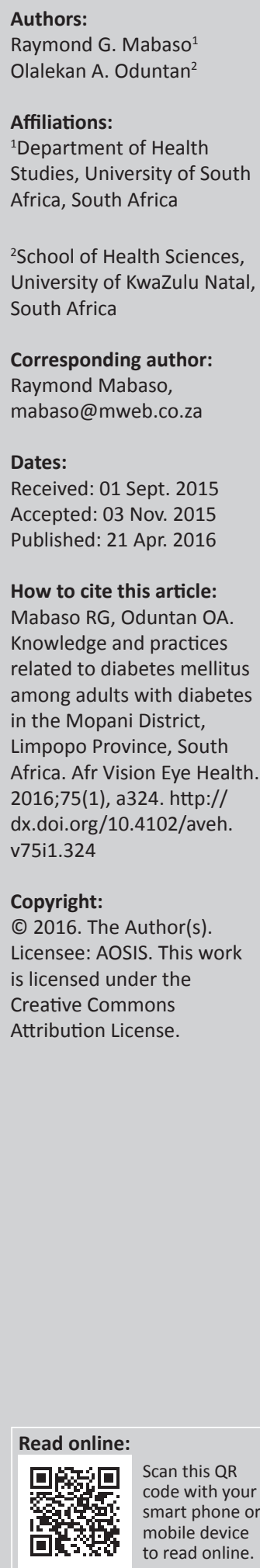

Background: Diabetes mellitus (DM) among black South Africans is on the increase because of population ageing, unhealthy lifestyles, and obesity. Knowledge about DM and appropriate practices related to DM are keys to its proper management.

Aim: To assess the knowledge and practices related to DM among black South Africans aged 40 years and older with DM.

Setting: The study was conducted in seven government health care facilities in the Mopani District.

Method: This was a health facility-based cross-sectional quantitative study. Structured interviews were used to obtain information which included socio-demographic profiles as well as knowledge about DM and its ocular complications.

Results: Participants $(N=225)$ included $161(71.6 \%)$ women and $64(28.4 \%)$ men aged 40-90 years (mean and standard deviation of $61.5 \pm 10.49$ years). Many $(68.3 \%)$ did not know the types of DM and only $32.4 \%$ knew the type of DM they had. Many knew about the importance of special diet $(84.5 \%)$ and physical activity $(64.4 \%)$ in DM management; however, only $52 \%$ knew about the importance of losing weight. Many (71.5\%) followed a special diet as advised, only $29.1 \%$ always tried to lose weight, and $48.3 \%$ engaged in physical activity. Many (82.6\%) knew that DM could cause vision problems, but only $49.3 \%$ have had their eyes examined. Most $(99.5 \%)$ of those on oral medication and those on insulin (93.1\%) reported using their treatment as prescribed.

Conclusion: The knowledge and practices related to DM among the participants were good in certain aspects but poor in others, suggesting the need for programmes on DM awareness in this population.

\section{Introduction}

Diabetes mellitus (DM) is a common metabolic disorder characterised by sustained hyperglycaemia of varying severity secondary to lack and/or diminished efficacy of endogenous insulin. ${ }^{1,2}$ The two major types of DM are Type 1 (insulin dependent) DM and Type 2 (non-insulin dependent) DM. ${ }^{3}$ Type $1 \mathrm{DM}$ (T1DM) is characterised by an autoimmune destruction of beta cells, which leads to absolute insulin deficiency and dependence on insulin injections for survival., ${ }^{2,4}$ Type 2 DM (T2DM) results from insulin resistance and relative insulin deficiency. ${ }^{2,4} \mathrm{~T} 2 \mathrm{DM}$ is the most common form of DM and can be controlled through healthy diet, physical activity, losing excess weight, and oral medication. ${ }^{5}$ Gestational DM occurs only during pregnancy and is a risk factor for T2DM after pregnancy. ${ }^{2,6}$ Other specific types of DM may result from causes such as genetic defects in beta cell function, insulin action, pancreatic diseases, and drug- or chemical-induced DM (such as with HIV medication). ${ }^{2,4}$

The prevalence of DM continues to increase worldwide, with developing countries being the most affected. Globally, the number of adults with DM aged 20-79 years was estimated as 387 million (8.3\%) in 2013, and future projections indicate that the number could reach 592 million $(10.1 \%)$ by 2035 , with $77 \%$ of them living in low-and middle-income countries. ${ }^{7}$ In the African continent the number of adults (20-79 years) with DM was estimated as 21.5 million (5.1\%) in 2014 and is expected to reach 41.5 million by $2035 .{ }^{7}$ In South Africa, the number of adults (20-79 years) with DM was estimated as 2.7 million (8.4\%) in 2014 and will almost double by 2035 if appropriate measures are not taken to prevent further proliferation of this condition. ${ }^{7}$ Population ageing, unhealthy diet, obesity, and sedentary lifestyles have been implicated as the causes of the global increase in the prevalence of DM, especially T2DM. ${ }^{8}$ 
Knowledge is the greatest weapon in the fight against DM. It is therefore imperative that people with DM and their family members understand the basic facts, such as the type they have, signs and symptoms, treatments, preventive measures, and the importance of maintaining good glycaemic control. Well-informed people would be motivated to assess their risk for the disease, seek proper treatment and care, and take charge of their disease. ${ }^{9}$ Knowledge about DM and its complications could also assist in the early detection of the disease and reduce the incidence of its complications. ${ }^{10}$ This would further encourage the individuals to be cautious about the disease and to seriously consider recommendations about prevention of DM. ${ }^{11}$

Studies ${ }^{11,12,13,14,15}$ in other countries have shown that the majority of the participants had poor knowledge about DM, with some believing that DM is caused by excessive sugar intake. ${ }^{11,14}$ However, some studies ${ }^{16,17}$ reported good DM knowledge. Also, some studies reported poor practices regarding blood glucose monitoring,,$^{10,14,18,19}$ eye examinations, ${ }^{15}$ diet, ${ }^{10,14,19}$ exercise, ${ }^{14,18,19}$ and losing weight ${ }^{14}$ in the management of DM, whereas others reported good practices regarding exercise, ${ }^{10}$ diet, and taking medication as prescribed..$^{18}$

In South Africa, studies $20,21,22$ have reported poor knowledge about DM, whereas another study ${ }^{23}$ reported good knowledge about the disease. Some studies reported poor practices regarding physical exercises, ${ }^{20,21,22}$ eye examinations, ${ }^{20,21,23}$ and glucose monitoring ${ }^{20,21}$ in the management of DM. However, good practices regarding diet, ${ }^{21,23}$ blood glucose monitoring, ${ }^{23}$ and taking medication as prescribed ${ }^{20}$ have also been reported.

No previous report could be found on knowledge and practices related to DM among diabetic patients in the Limpopo Province, South Africa. Such a report could be useful to the health authorities in planning for awareness campaigns about the disease. Therefore, the aim of this study was to assess the knowledge and practices related to DM among black South Africans aged 40 years and older with DM in the Mopani District, Limpopo Province.

\section{Research design and methods Study design}

This was a cross-sectional, health facility-based, quantitative study.

\section{Setting}

The study was conducted in the Mopani District Municipality in the Limpopo Province. The district has a population of about 1 million people, with $81 \%$ residing in the rural areas. ${ }^{24}$ Approximately $73 \%$ of the population is unemployed and more than half of the adult population is illiterate. ${ }^{23}$ The study was conducted in seven government health facilities, which included four clinics, two hospitals, and one health centre. $^{2}$ During the period of this study (May-December 2011), the total number of black South Africans with DM recorded in the chronic diseases registers at the targeted health facilities was 721. Of this number, 25 (3.5\%) were $<40$ years and these included 15 women and 10 men. Others (696 [96.5\%]) were $\geq 40$ years and were mostly $(N=475$; $68.2 \%)$ women. ${ }^{2}$

\section{Study population and sampling strategy}

The population included black South Africans of both sexes with DM, aged 40 years and older, receiving DM treatment from the targeted health care facilities. The inclusion criteria included being black South Africans aged 40 years and older with DM and willing to participate and sign the necessary consent forms. All those who were recruited participated in the study. ${ }^{2}$ Convenience sampling was used to select participants from the targeted facilities. This sampling method is one of the non-probability sampling methods, which involves the use of the most conveniently available people as study participants. ${ }^{2,25}$ The advantages of this method include ease of recruitment, easier monitoring and follow-up, generally good response rates, and retention of sample members. ${ }^{2,25}$ The plan was to have an equal number of participants from each health facility, but that was not possible because the number of diabetic patients varied significantly from one facility to another. ${ }^{2}$ Based on an estimate of $15 \%$ of participants having good knowledge and ensuring good practices regarding DM, the calculated sample size was 195 as shown in the formula below. However, 225 participants were included in this study:

$N=z^{2 *} \frac{[P(1-P)]}{D^{2}}$

[Eqn 1]

Where, $N=$ sample size required; $Z^{*} Z=95 \%$ confidence level $=1.96$ (two tail); $P=$ proportion of those with good knowledge and practice $=0.15 ; D^{2}=$ acceptable error $=0.0025$.

\section{Data collection}

Structured interviews were used to collect information, which included socio-demographic profiles and knowledge about DM and its ocular complications. The interview schedule included questions about the duration, types of $\mathrm{DM}$, treatment and compliance to treatment, place where blood glucose is checked, and the last time they checked their blood glucose. Questions on knowledge about the ocular complications of DM, eye examination history, and family history of DM were also asked.

\section{Data analysis}

The responses from the interview were collated and analysed descriptively using the Statistical Analysis System (SAS) version 9.2 and Microsoft Excel 2013 software packages.

\section{Ethical considerations}

This study was approved by the Health Studies Research and Ethics Committee, University of South Africa 
(Project number: 0729-138-8), and permission was obtained from the relevant authorities before the commencement of the study. ${ }^{2}$ The study was conducted in accordance with the World Medical Association Declaration of Helsinki on the ethical principles for medical research involving human subjects. All the approved ethical protocols were observed during the study.

\section{Results}

Of the 225 participants, 161 (71.6\%) were women and 64 (28.4\%) were men. Their ages ranged from 40-90 years (mean and $\mathrm{SD}=61.5 \pm 10.49$ years). ${ }^{2}$ More than half $(55.1 \%)$ of the participants were married, whereas 21.8, 13.8 and 9.3\%, respectively, were widowed, single, and divorced. Many $(68.9 \%)$ resided in rural areas and only a few $(0.4 \%)$ resided in the urban areas. The percentages of those who resided in semi-urban and informal settlements were 28.4 and 2.3\%, respectively. The other socio-demographic characteristics are shown in Table 1.

Nearly $40 \%(39.6 \%)$ of the participants reported that they have had DM for less than 5 years and only $9.3 \%$ reported having had the disease for more than 15 years (Figure 1). Many (68.3\%) did not know the types of DM (Figure 2). More than two thirds $(67.6 \%)$ did not know the type they had; $28 \%$ reported having type 2 , and $4.4 \%$ reported having type 1 .

Most participants $(84.6 \%)$ used only oral medication to control their DM, $10.3 \%$ used only insulin injections,

TABLE 1: Socio-demographic characteristics of the study participants.

\begin{tabular}{|c|c|c|c|}
\hline Characteristics & Variable & $N$ & $\%$ \\
\hline Sex & Women & 161 & 71.6 \\
\hline \multirow[t]{6}{*}{ Age (years) } & $40-44$ & 13 & 5.8 \\
\hline & $45-49$ & 12 & 5.3 \\
\hline & $50-54$ & 36 & 16 \\
\hline & $55-59$ & 32 & 14.2 \\
\hline & $\geq 60$ & 123 & 54.7 \\
\hline & Unknown & 9 & 4 \\
\hline \multirow[t]{4}{*}{ Level of education } & No formal education & 58 & 25.6 \\
\hline & Primary school & 93 & 41.3 \\
\hline & High school & 59 & 26.2 \\
\hline & Tertiary & 14 & 6.7 \\
\hline \multirow[t]{5}{*}{ Occupation } & Professionals & 8 & 3.6 \\
\hline & Self-employed & 7 & 3.1 \\
\hline & Labourers & 29 & 12.9 \\
\hline & Pensioners & 136 & 60.4 \\
\hline & Unemployed & 45 & 20 \\
\hline \multirow[t]{5}{*}{ Monthly income } & No income & 34 & 15.1 \\
\hline & R0-R500 & 15 & 6.7 \\
\hline & R501-R1000 & 15 & 6.7 \\
\hline & R1001-R2000 & 125 & 55.6 \\
\hline & $>\mathrm{R} 2000$ & 36 & 16 \\
\hline \multirow[t]{5}{*}{ Source of income } & No income & 23 & 10.2 \\
\hline & Informal settlements & 21 & 9.3 \\
\hline & Formal employment & 19 & 8.4 \\
\hline & Government social grants & 22 & 9.8 \\
\hline & Old-age pension & 138 & 61.3 \\
\hline
\end{tabular}

$N=225$.

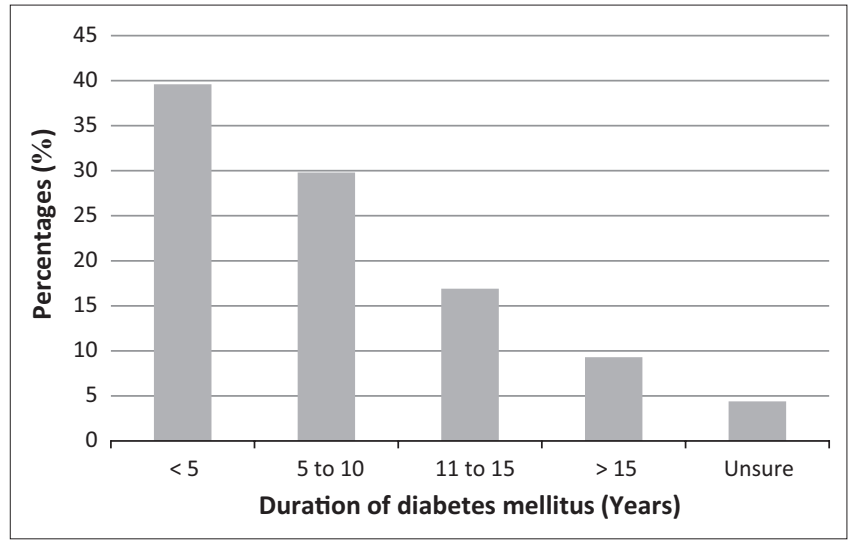

FIGURE 1: The duration of diabetes mellitus and the percentages of the participants.

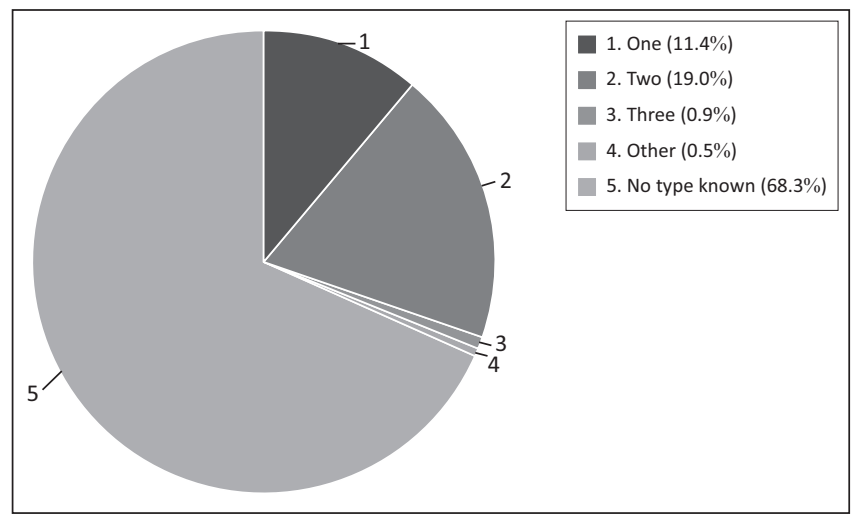

FIGURE 2: The number of types of diabetes mellitus known and the percentages of the participants.

and $5.1 \%$ used a combination of these. Most (99.5\% of those using oral medication and $93.1 \%$ of those using insulin) reported that they always used their treatment as prescribed. Most $(84.5 \%)$ knew the importance of special diet in the control of DM, and of these, $71.5 \%$ reported that they followed special diet as advised, whereas others (28.5\%) did not. Only $52 \%$ knew the importance of losing weight in the control of DM. Of these, only $29.1 \%$ reported that they were always trying to lose weight. The other responses are shown in Table 2. Many (64.4\%) knew the importance of physical activity in the control of DM, and of these, $48.3 \%$ reported that they always engaged in physical activity. Other responses are shown in Table 3.

Many $(87.1 \%)$ of the participants last checked their blood glucose less than 1 month prior to the interview (Table 4). Many $(82.6 \%)$ knew that DM could cause vision problems and blindness; 74.4 and 53.1\%, respectively, knew that DM could cause diabetic retinopathy (DR) and glaucoma. Only about half $(49.3 \%)$ of the participants have had their eyes examined by an ophthalmologist or optometrist. The times of the last eye examination are illustrated in Figure 3. More than half $(52.7 \%)$ of the participants had a family history of DM, whereas $37.7 \%$ did not. About 10\% (9.6\%) were not sure if they had a family history of the condition or not. About a third (31.6\%) reported that their family members with DM had visual impairment, 53.2\% did not and 15.2\% were not sure. 
TABLE 2: The distribution of participants according to their compliance to losing weight.

\begin{tabular}{lcc}
\hline Compliance to losing weight & $\boldsymbol{N}$ & $\mathbf{\%}$ \\
\hline Yes, always & 34 & 29.1 \\
Yes, but not always & 53 & 45.3 \\
Do not lose weight at all & 30 & 25.6 \\
\hline Total & $\mathbf{1 1 7}$ & $\mathbf{1 0 0}$ \\
\hline
\end{tabular}

TABLE 3: The distribution of participants according to compliance to physical activity.

\begin{tabular}{lcc}
\hline Compliance to physical activity & $\boldsymbol{N}$ & $\mathbf{\%}$ \\
\hline Yes, always & 70 & 48.3 \\
Yes, but not always & 52 & 35.9 \\
Do not lose weight at all & 23 & 15.9 \\
\hline Total & $\mathbf{1 4 5}$ & $\mathbf{1 0 0}$ \\
\hline
\end{tabular}

TABLE 4: The last time of blood glucose check up, number of participants $(N)$, and percentages $(\%)$

\begin{tabular}{lcc}
\hline Last check up & $\boldsymbol{N}$ & $\mathbf{\%}$ \\
\hline$<1$ Week & 5 & 2.2 \\
$<1$ Month & 195 & 87.1 \\
$<6$ Month & 23 & 10.3 \\
$<1$ year & 0 & 0 \\
$\geq 1$ year & 1 & 0.5 \\
\hline Total & $\mathbf{2 2 4}$ & $\mathbf{1 0 0}$ \\
\hline
\end{tabular}

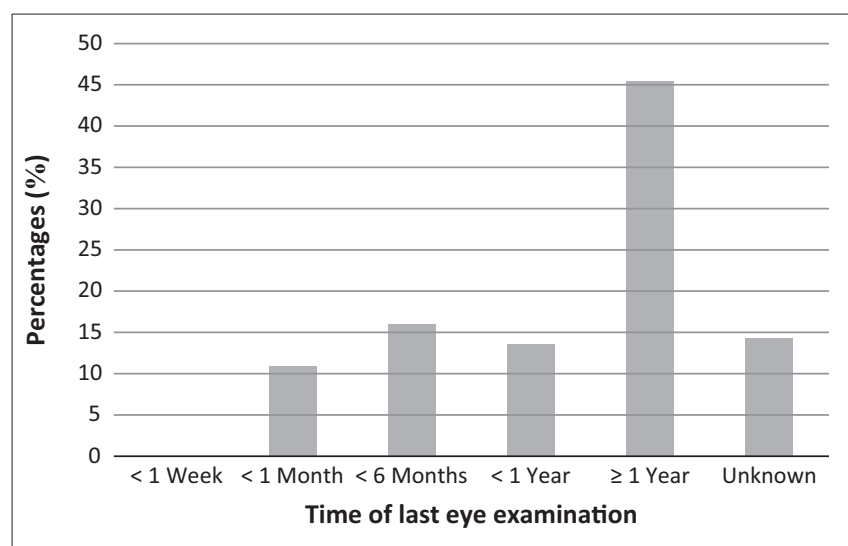

FIGURE 3: Time of the last eye examination and the percentages of the participants.

\section{Discussion}

$\mathrm{DM}$ is one of the most common causes of morbidity and mortality worldwide. Because of lack of knowledge about this disease, many diabetic patients suffer from its complications. ${ }^{8}$ In this study, there were more women than men, a finding that is consistent with reports from other studies $^{21,23}$ as well as with the South African demographics. ${ }^{26}$ Contrarily, Phillips et al. ${ }^{20}$ reported more men than women. The differences may be that the study used a relatively small sample size from one optometric practice.

Many of the participants in this study were in the older age group which is consistent with findings from other studies. ${ }^{21,23,27}$ The high proportion in the older age group ( $\geq 60$ years) in the present study suggests that older people in rural areas are more likely to utilise the government health services than the younger age groups. It also supports the view that the prevalence of DM increases with age. ${ }^{8}$
The higher proportion of married participants than the other marital status categories is consistent with a previous report ${ }^{14}$ as well as the population census. ${ }^{26}$ In agreement with previous studies, ${ }^{21,23}$ many of the participants in the present study were pensioners. The high percentage of pensioners may be because almost $70 \%$ of the participants in these studies were 50 years and older. That many (41.3\%) of the participants in this study had only primary education, whereas only a few had tertiary education, agrees with a report from a previous study. ${ }^{22}$ Contrarily, Phillips et al. ${ }^{20}$ reported low $(4.1 \%)$ and high $(31.5 \%)$ percentages of those with primary and tertiary education, respectively. The differences may be attributed to the several socio-economic disparities between the two population samples.

That many (69\%) of the participants were earning R2000 or less agrees with a report from a previous study. ${ }^{22}$ The explanation for the low income may be that the majority of our study participants were receiving an old-age pension, which in April 2012 was increased to R1200 per month. ${ }^{28}$ That many (68.9\%) of the participants lived in the rural areas is consistent with a report from the Limpopo Province population census data. ${ }^{29}$ The smaller proportion of those who have had DM for more than 15 years than those who have had the disease for less than 5 years is in agreement with findings from a previous study. ${ }^{23}$ The low proportion of those with longer duration may be that, in the past, DM was not prevalent among rural black South Africans. ${ }^{30}$ Sadly, because of westernisation (e.g. replacement of traditional African diet with Western-style diets) of the rural communities, this disease is increasingly becoming more prevalent among the rural black South Africans. ${ }^{30}$

Knowledge about the types of DM among the participants in this and another study ${ }^{15}$ was considered inadequate. This is of concern because the type that an individual suffers from has implications for the management strategies and the period of onset of ocular complications. It has been estimated that up to $21 \%$ of T2DM patients develop DR at the time of diagnosis, whereas DR is rare 3-5 years after diagnosis of T1DM. ${ }^{31}$ Some studies ${ }^{20,21,23}$ reported higher proportions $(42 \%-96 \%)$ of participants who knew the two main types of DM than the $19 \%$ reported in this study. The differences in the knowledge levels may be attributed to the serious inequalities with regard to access to proper education, health services, and health education during the apartheid era. ${ }^{32}$

The majority of the participants in this study reported using their treatment as prescribed, which is consistent with previous studies. ${ }^{18,20}$ The percentage $(15.4 \%)$ of those using insulin in this study is comparable to the $15.3 \%$ reported in a previous study, ${ }^{33}$ but higher than that from other studies. ${ }^{34,35}$ The percentage of those using oral medication was higher than what was reported in other studies, ${ }^{27,34}$ but comparable to the $88 \%$ reported in another study. ${ }^{35}$

Several studies have shown that appropriate lifestyle changes may help to prevent or delay the incidence of T2DM in high-risk individuals. Special diet, exercises, diet plus 
exercise $^{36}$ and losing excess weight ${ }^{37}$ result in a significant reduction in the incidence of T2DM. These lifestyle changes are generally recommended for use in combination with the medical treatment (insulin injection, oral medication, or both), as was the case in this study's participants. The explanation for the recommendation is probably because lifestyle changes alone fail to achieve or maintain the metabolic goals because of failure in losing weight, regaining weight, disease progression, or a combination of factors. ${ }^{38}$

The knowledge among the participants regarding the importance of special diet (84.5\%) and physical activity $(64.4 \%)$ to control hyperglycaemia was considered adequate; however, their knowledge regarding losing weight (52\%) was considered inadequate. Their practices regarding special diet were good and about three quarters reporting that they always followed a special diet, a finding consistent with that from other South African studies..$^{18,20,21,23}$ However, the practices regarding losing weight were considered poor with only $29.1 \%$ reporting that they were always trying to lose weight. These findings are consistent with those from previous studies. ${ }^{14,22}$ The practices regarding physical activity were also considered poor, and $48.3 \%$ reporting that they always engaged in physical activity. These findings are consistent with those from previous studies. ${ }^{13,18,20,21,22}$ Other studies ${ }^{10,23}$ reported good practices regarding physical activity.

Many (87.1\%) participants in this study reported that they checked their blood glucose less than a month prior to the interview. This finding is consistent with a report from a previous study. ${ }^{18}$ Most (99.5\%) of the participants in this study only checked their blood glucose once a month at the health facilities when they go for treatment. Therefore, the participants' practices towards blood glucose monitoring may be considered good, as they always honoured their appointment with the health facilities. However, the time interval (once a month) between follow-ups is too long, considering the fact that blood glucose may increase or decrease at any time, sometimes with disastrous consequences. Phillips et al. ${ }^{20}$ reported poor practices regarding blood glucose monitoring as only $21 \%$ had daily blood glucose tests despite $82 \%$ of them having glucometers.

The knowledge about some ocular complications of DM was considered adequate as $82.6 \%$ and $74.4 \%$ of the participants knew that DM could cause vision problems and DR, respectively. However, their knowledge about DM as a cause of glaucoma (53.1\%) was considered inadequate. A previous study ${ }^{23}$ reported higher figures of those who knew that DM could cause vision problems and DR than those reported in this study. Clarke-Farr et al. ${ }^{21}$ reported a higher figure of those who knew that DM could cause glaucoma than that reported in this study.

Regular eye examinations in general, and among persons with diabetes in particular, are important in the prevention of visual impairment and blindness. Early detection and treatment of DR may reduce the risk of visual impairment and blindness. ${ }^{39}$ In addition, the incidence and prevalence of diabetic blindness is lower in populations with wellestablished screening programmes compared with those without such programmes. ${ }^{39}$ Hence, the authors agree with the recommendation that T1DM patients should have their first dilated fundus examination 3-5 years after diagnosis and T2DM patients should have their first examination at diagnosis. ${ }^{31}$

In agreement with a previous study, ${ }^{23}$ many participants in the present study had their last eye examination more than a year prior to the interview. About two thirds (65.8\%) of the participants reported that they had eye examination only when they had poor vision. ${ }^{15}$ This does not augur well for people with DM as regular eye examination is an important factor in the prevention of the ocular complications of this condition. ${ }^{23}$

\section{Strengths and limitations}

This study is the first to assess the knowledge and practices regarding DM among black South Africans with DM in a predominantly rural district of Limpopo Province and therefore provides valuable data on the levels of knowledge in the community. However, the fact that this study was conducted in government health facilities and not population-based could have introduced a health-seeking bias. The larger proportion of older, unemployed, and poor participants; and there being more women than men in this study; could also introduce some bias. ${ }^{2}$ The higher proportion of women compared to men could be because those who were employed (mostly men) might have been at work when the study was conducted, or it might mean that men do not survive DM as well as women. In addition, individuals in formal employment (mostly men) tend to have medical aid schemes and therefore use private health services. It is acknowledged that the study population is not necessarily fully representative of the entire population of persons with $\mathrm{DM}$ in the Mopani District or Limpopo Province. ${ }^{2}$

\section{Recommendations}

Based on the findings in this study, it is recommended that a population-based study be conducted to assess the knowledge and practices related to DM in this community. If such a study reveals poor knowledge and practices related to this condition, then awareness-raising campaigns should be initiated to educate people on the types of DM, signs and symptoms, treatments, and the importance of lifestyle changes in the prevention and management of DM.

\section{Conclusion}

This study showed that the knowledge about DM types and losing weight in DM management among the participants was inadequate. Although many participants had good knowledge about the importance of special diet and physical exercises in DM management, their practices regarding losing weight, physical exercises, eye examinations, and 
glucose monitoring were poor. There may be a lack of patient education regarding DM and its management in Mopani District, or may it be that the patients could not understand what they were taught as many of them were illiterate. The past Bantu education system, which deliberately provided inferior education to black people, may have contributed to the poor DM knowledge and practices in this population.

\section{Acknowledgements}

The work reported in this article is part of a D.Litt. et Phil project. Authors thank Idon Sibuyi (optometrist) for helping with data collection. We express our gratitude to P Ndlovu and MA Managa (statisticians) for helping with data analysis. In addition, we thank the peer reviewers of this article.

\section{Competing interests}

The authors declare no competing interests.

\section{Authors' contributions}

R.G.M. was responsible for the project design, data collection, analysis and writing of the manuscript under the supervision of O.A.O.

\section{References}

1. Kanski JJ. Clinical ophthalmology: A systematic approach. 5th ed. London: Butterworth-Heinemann; 2003.

2. Mabaso RG, Oduntan OA. Risk factors for visual impairment and blindness amongst black adult diabetics receiving treatment at Government healthcare facilities in Mopani District, Limpopo province, South Africa. Afr J Prm Health Care Fam Med. 2014; 6 (1), Art. \#623, 8 pages. http://dx.doi.org/10.4102/phcfm.v6i1.623

3. World Health Organization. Laboratory diagnosis and monitoring of diabetes mellitus. Geneva: Bulletin of the World Health Organization, 2002; pp. 1-12.

4. American Diabetes Association. Diagnosis and classification of diabetes mellitus. Diabetes Care. 2010;33:S62-S69.

5. Centres for Disease Control and Prevention. National diabetes fact sheet: National estimates and general information on diabetes and pre-diabetes in the United States [homepage on the Internet]. 2012 [cited 2012 Jan 20]. Available from: http://www.cdc.gov/diabetes/pubs/pdf/ndfs_2011

6. Buchanan TA, Xiangh AH. Gestational diabetes mellitus. J Clin Invest. 2005; 115:485-491.

7. International Diabetes Federation. 2014 update [homepage on the Internet] Diabetes Atlas. 6th ed. 2014 [cited 2015 Aug 29]. Available from: https://www.idf. org/sites/default/files/Atlas-poster-2014_EN.pdf

8. Wild S, Roglic G, Green A, Sicree R, King H. Global prevalence of diabetes: Estimates for the year 2000 and projections for 2030. Diabetes Care. 2004;27:1047-1053.

9. Lushen M, Rambiritch V. An assessment of the level of knowledge about diabetes mellitus among diabetic patients in a primary healthcare setting. S Afr Fam Pract. 2007; 49:16a-16d.

10. Saleh F, Mumu SJ, Ara F, Begum HA, Ali L. Knowledge and self-care practices regarding diabetes among newly diagnosed type 2 diabetics in Bangladesh: A crosssectional study [homepage on the Internet]. BMC Public Health. 2012;12:1112. Available from: http://www.biomedcentral.com/1471-2458/12/1112

11. Ahmad S, Srivastava A, Goel K, Parashar P, Bansal R, Pant B. Knowledge and awareness regarding diabetes mellitus in urban slum of Meerut. Indian Community Health. 2013;25:12-15.

12. Gul N. Knowledge, attitudes and practices of Type 2 diabetic patients. J Ayub Med Coll Abbottabad. 2010;22:128-131.

13. Maina WK, Ndegwa ZM, Njenga EW, Muchemi EW. Knowledge, attitude, and practices related to diabetes among community members in four provinces in Kenya: A cross-sectional study. Afr J Diabetes Med. 2011;19:15-18.
14. Al-Maskari F, El-Sadig M, Al-Kaabi JM, Afandi B, Nagelkerke N, Yeatts KB. Knowledge, attitude and practices of diabetic patients in the United Arab Knowledge, attitude and practices of diabetic patients in the United Arab
Emirates. PLoS One. 2013;8:e52857. http://dx.doi.org/10.1371/journal.pone. Emirates.
0052857

15. Ovenseri-Ogbomo GO, Abokyi S, Koffuor GA, Abokyi E. Knowledge of diabetes and its associated ocular manifestations by diabetic patients: A study at Korle-Bu Teaching Hospital, Ghana. Niger Med J. 2013; 54:217-223.

16. Perera DP, De Silva RE, Perera WL. Knowledge of diabetes among type 2 diabetes patients attending a primary health care clinic in Sri Lanka. East Mediterr Health J. 2013;19:644-648.

17. Ayele K, Tesfa B, Abebe L, Tilahun T, Girma E. Self-care behaviour among patients with diabetes in Harari, Eastern Ethiopia: The health belief model perspective. PLoS One. 2012;7:e35515. http://dx.doi.org/10.1371/journal.pone.0035515

18. Raj CKP, Angadi MM. Hospital-based KAP study on diabetes in Bijapur, Karnataka. Indian J Med Spec. 2010;1:80-83.

19. Ng SH, Chan KH, Lian ZY, Chuah YH, Waseem AN, Kadirvelu A. Reality vs illusion: Knowledge, attitude and practice among diabetic patients. Int J Collaborative Res Intern Med Public Health. 2012;4:723-732.

20. Phillips KC, Mashige KP, Clarke-Farr PC. Knowledge of diabetes mellitus in privately-funded diabetic patients attending a rural optometric practice in Malmesbury, South Africa. S Afr Optom. 2012;71:70-77.

21. Clarke-Farr PC, Nel MM, Wilkinson AC. An investigation into diabetic patients knowledge of diabetes and its ocular complications in the Western Cape. S Afr Optom. 2006;65:134-143.

22. Okonta HI, Ikombele JB, Ogunbanjo GA. Knowledge, attitude and practice regarding lifestyle modification in type 2 diabetic patients. Afr J Prim Health Care Fam Med. 2014;6(1):E1-E6. http://dx.doi.org/10.4102/phcfm.v6i1.655.

23. Mashige KP, Notshweleka A, Moodley $S$, et al. An assessment of the level of diabetic patients' knowledge of diabetes mellitus, its complications and management in Durban, South Africa. S Afr Optom. 2008;67:95-105.

24. Mopani District Municipality. 2009. Reviewed integrated development plan 2006-2012.

25. Bowling A. Research methods in health: Investigating health and health studies. 2nd ed. Berkshire: Open University Press; 2002.

26. Statistics South Africa. Provincial profile, Limpopo [homepage on the Internet] 2004 [cited $2012 \mathrm{Jul}$ 10]. Available from: http://www.statssa.gov.za/publications/ Report-00-091-092004.pdf

27. Onakpoya $\mathrm{OH}$, Adeoye AO, Kolawole BA. Determinants of previous dilated eye examination among type II diabetics in Southwestern Nigeria. Eur J Intern Med. 2010; 21:176-179.

28. South African Government services. Older persons grant [homepage on the Internet]. 2012 [cited 2012 Aug 23]. Available from: http://www.services.gov.za/ services/content/Home/ServicesForPeople/Retirementandoldage/en_ZA

29. Limpopo Department of Health and Social Development 2011/12-2013/14. Annual performance plan vote 7: Health [homepage on the Internet]. 2011. [cited 2011 Sep 22]. Available from: http://www.dhsd.limpopo.gov.za/docs/reports/final

30. Moodley LM, Rambiritch V. An assessment of the level of knowledge about diabetes mellitus among diabetic patients in a primary healthcare setting. S Afr Fam Pract. 2007; 49:16.

31. Fong DS, Aiello L, Gardner TW, et al. Diabetic retinopathy. Diabetes Care. 2003;26:s99-s102.

32. Coovadia $H$, Jewkes $R$, Barron $P$, Sanders $D, M c I n t y r e ~ D$. The health and health system of South Africa: Historical roots of current public health challenges. Lancet. 2009;374:817-834.

33. McCarty DJ, Fu CL, Harper CA, Taylor HR, McCarty CA. Five-year incidence of diabetic retinopathy in the Melbourne visual impairment project. Clin Exp Ophthalmol. 2003;31:397-402.

34. Smith TS, Szetu J, Bourne RR. The prevalence and severity of diabetic retinopathy, associated risk factors and vision loss in patients with type 2 diabetes in Luganville, Vanuatu. Br J Ophthalmol. 2007;91:415-419.

35. Sobngwi E, Ndour-Mbaye M, Boateng KA, et al. Type 2 diabetes control and complications in specialised diabetes care centres of six sub-Saharan African countries: The Diabcare Africa study. Diabetes Res Clin Pract. 2012;95:30-36.

36. Pan XR, Li GW, Hu YH, et al. Effects of diet and exercise in preventing NIDDM in people with impaired glucose tolerance. The Da Qing IGT and diabetes study. Diabetes Care. 1997;20:537-544.

37. Long SD, O'brien K, Macdonald KG, et al. Weight loss in severely obese subjects prevents the progression of impaired glucose tolerance to type 2 diabetes. Diabetes Care. 1994;17:372-375.

38. Nathan DM, Buse JB, Davidson MB, et al. Medical management of hyperglycemia Type 2 diabetes: A consensus algorithm for the initiation and adjustment of therapy. Diabetes Care. 2009;32:193-203.

39. Stefansson E, Bek T, Porta M, Larsen N, Kristinsson JK, Agardh E. Screening and prevention of diabetic blindness. Acta Ophthalmol Scand. 2000;78:374-385. 